\title{
Ann Arbor Stage III Noncutaneous Childhood Anaplastic Large Cell Lymphoma
}

National Cancer Institute

\section{Source}

National Cancer Institute. Ann Arbor Stage III Noncutaneous Childhood Anaplastic Large

Cell Lymphoma. NCI Thesaurus. Code C115031.

Ann Arbor Classification: Stage III: Involvement of lymph node regions on both sides of the diaphragm (III), which also may be accompanied by extralymphatic extension in association with adjacent lymph node involvement (IIIE) or by involvement of the spleen (IIIS) or both (IIIE,S). 